\title{
CoRPo tRANSGRESSÃo: A VIOLÊnCIA tRADUZIDA NAS PERFORMANCES dO Coletivo Coiote, Bloco Livre Reciclato e Black Blocs
}

Camile Vergara

UERJ, Rio de Janeiro, Brasi ${ }^{1}$

\begin{abstract}
Este artigo, situado nas áreas de antropologia visual e estudos de performances, busca analisar a noção de "Corpo Transgressão" na perspectiva da elaboração de um corpo insurgente, rebelde, não submisso. Trata-se de um estudo etnográfico dos movimentos insurgentes Bloco Livre Reciclato, Coletivo Coiote e Black Blocs. Essas performances podem ser definidas como uma economia politica voltada para a transformação na forma de gestão dos corpos. Esta perspectiva carrega o sentido da resistência e da desconstrução da noção de corpo dócil formulada por Foucault. O cenário das performances e manifestações foram as ruas no Rio de Janeiro. A análise aparece vinculada ao campo semântico da estética da violência e são estudados os movimentos de insurgência a partir das imagens-violência traduzidas nas performances.
\end{abstract}

Palavras chave: corpo transgressão, performance, insurgência, imagem-violência, agenciamentos

\section{INTRODUÇÃO}

Este artigo, situado nas áreas de antropologia visual e estudos de performances analisa a noção de "Corpo Transgressão". ${ }^{2}$ Essa noção carrega a ideia de desconstrução do corpo dócil, segundo a concepção formulada por Foucault (1988). A desconstrução tem como contexto a

1 Mestranda no Programa de Pós-graduação em Ciências Sociais na Universidade do Estado do Rio de Janeiro (PPCIS/UERJ). Orientadores: Clarice Ehlers Peixoto e Marcos Albuquerque. Bolsista capes. Esta pesquisa inclui um documentário remix realizado em coautoria com o Coletivo Antena Mutante (Colômbia). Link para o filme Corpo Transgressão: https://www.youtube.com/watch?v=Jxe5y0gvwAg. Contato do autor: camilevergara@gmail. com

2 Esse artigo é parte da pesquisa em andamento "Corpo Transgressão: Manifestos Performances (Um estudo da economia política do corpo em performances de rua no Rio de Janeiro). 
perspectiva da emergência de um corpo insurgente, rebelde, não submisso. $\mathrm{O}$ corpo e sua relação com o espaço/cidade em fluxos que atravessam os espaços virtuais, as "redes" e as "malhas". ${ }^{3}$

A desterritorialização material, provocada nas performances, constitui em um movimento de atualização em que a prática espacial destitui a representação. Desta maneira se estabelece um eixo entre a vida aorgânica, a rede (net) e a prática espacial na ocupação das ruas (malhas). O “Corpo Transgressão" como dispositivo da vida aorgânica (Lazzarato: 2006), como estratégia de transbordamento, ocupando o espaço e enfatizando uma política da diferença.

As performances situam também o que Judith Butler (2015) considera uma vida precária enquanto agenciamentos não identitários, a vulnerabilidade da vida com relação às violências que atravessam os atores. Neste sentido, as performances traduzem as violências, mas também estabelecem certos fluxos de vitalidade criativos com o intuito de tornar a revolta contagiante. ${ }^{4}$

As vivências como performer e antropóloga, observações e registros das entrevistas com estudantes, professores, militantes dos movimentos de ocupações, os agentes criadores e realizadores das performances constituíram as bases deste estudo etnográfico realizado com os movimentos insurgentes Bloco Livre Reciclato, Coletivo Coiote e o uso da tática Black Bloc. ${ }^{5}$ Os coletivos citados são formas diferentes de performances que se constituem em situações emergenciais relacionadas a violência urbana.

O Bloco Livre Reciclato é aberto, em forma de bloco, os transeuntes são convidados a participar. Uma mistura de manifestação, ação direta e teatral, o bloco se agrupa desde 2012 na Lapa, sempre no dia dos mortos, ou em solidariedade a manifestações populares relacionadas aos movimentos urbanos de ocupação.

O Coletivo Coiote existe desde 2012 e realizam intervenções em espaços públicos, bares, festas e manifestações, se organiza de maneira aberta e horizontal agregando outros performers em seu trajeto nômade. Sua crítica é dirigida à heterossexualidade compulsória, à normalização e colonização dos corpos e à homofobia institucional.

A tática Black Bloc se popularizou no Brasil durante o processo das manifestações de 2013 em que os protestos eram principalmente contra o aumento das passagens e a violência policial. $\mathrm{O}$ uso de roupas e máscaras negras e organizado para o confronto visa manter a manifestação mais tempo na rua frente as investidas da polícia militar.

O que estas três manifestações têm em comum é o empoderamento pela violência, no sentido que desconstroem a passividade de seus corpos e utilizam a prática da ação direta para criação de uma "zona autônoma temporária" (Hakim Bey: 2004), momento "liminóide" (Turner: 1974) de alteração do espaço, do tempo e do inconsciente.

3 Rede e Malha são conceitos trabalhados por diferentes autores. Nesse trabalho adoto a perspectiva de rede como espaço da vida virtual ou a-orgânica de Maurizio Lazzarato (2006) e com a noção de malha de Henri Lefevbre (1986), na qual a virtualidade volta a estender-se como espaço físico.

4 A condição de sujeito, para Butler, é um diferencial de poder, o "eu" é produzido através do poder. Vulnerabilidade para a autora implica em um risco do "eu" e, portanto, da condição de sujeito, mas também a abertura para uma postura não egocêntrica, exposta ao outro.

5 Mais informações sobre os agenciamentos acessar: https://medium.com/@colombinasanglant/corpo-transgressao-performance-de-vida-e-morte-4e414597d95d. 
Essas performances podem ser definidas, como uma economia política do corpo voltada para a transformação na forma de gestão dos corpos. A perspectiva da destruição como produtora de energia e a noção de dispêndio (Bataille: 1975) são úteis para entender a atualização de um poder que as atravessa a maneira de ocupação do espaço e transgressão de fronteiras visíveis e invisíveis, para além da representação. Ao tratar de situações em que o consumo, a destruição e a violência estão em questão, esta perspectiva propícia o entendimento das performances enquanto produtoras de uma energia de contágio que se dá no transbordamento dos corpos pelas técnicas da reciclagem, da escatologia, da destruição e do ruído em um devir marcado pelo excesso. A radicalização da violência e da destruição implica na busca de uma estética da crueldade expressa nas performances e enunciada por uma economia política do corpo e de gestão contra a norma e o código.

Para Artaud (2006) "tudo que age é uma crueldade. É a partir dessa ideia de ação levada ao extremo que o teatro deve se renovar” (Artaud, 2006: 32) neste sentido as situações construídas carregam este caráter de destruição das formas humanas, de um devir monstro que aparece como empoderamento. A noção de monstruosidade está relacionada a subversão na afirmação da vulnerabilidade, as performances agenciam discursos marginais, traduzem as violências sofridas de modo a enfatizar e compartilhar a situação de morte em que se encontram e propõem resistências alegres às normas que os condenam. A monstruosidade é a mutação e exposição do corpo às trocas, no caso destes agenciamentos a exposição a devires cruéis impulsionam ações de ruptura, de rasgo e de ruído.

O estudo primeiramente corresponde à análise do campo semântico das estéticas de violência. Fazem parte desse campo comum e heterogêneo os diferentes sentidos de violência que se atualizam de forma processual a partir do fluxo de informações midiáticas, imagens e performances referentes ao contexto que perpassa as manifestações.

Em junho de 2013 o aumento da passagem de ônibus no Brasil provocou manifestações populares que começaram em São Paulo e se espalharam pelo país. Os atos se potencializaram em solidariedade a primeira manifestação que foi duramente reprimida pela polícia. As manifestações se estenderam e ganharam novas pautas relacionadas aos contextos das cidades em que aconteciam. No Rio de Janeiro agregou-se a greve geral da educação em outubro e em seguida as manifestações contra as desocupações provocadas pelas obras para o mundial de futebol que aconteceu no Brasil em 2014. As manifestações ocorriam semanalmente, nas segundas-feiras em locais periféricos (bairros e comunidades) e nas quintas-feiras no centro da cidade.

Este contexto é marcado pela efervescência dos movimentos sociais, emergência de organizações como a FIP $^{6}$ (Frente Independente Popular) e prática de ação direta, assembleias em espaços públicos e universidades, performances artísticas e eventos culturais contra a criminalização dos movimentos sociais e detenções de manifestantes em massa.

As performances atualizam as violências ligadas a colonização e a escravidão. Tradução, que segundo Lazzarato (2006), consiste em um ato de memória, em que o virtual é atualizado como ato de criação. Neste sentido, as performances, antes de reproduzir as identificações e simbolismos da semântica da violência, criam espaços suspensos de transmissão de afetos e

6 A Frente Independente Popular foi organizada por ativistas tendo como foco a crítica a farsa eleitoral, tendo como pratica a convocação de manifestações, assembleias e evento culturais em espaços públicos. 
retomada dos sentidos dessa violência.

O Rio de Janeiro, enquanto metrópole moderna e diante da globalização é um campo vasto de inspiração para aqueles que praticam o "teatro da vida" (Artaud: 2006). Trata-se de agentes que através de performances corporais constroem uma estética vinculada as diferentes opressões sofridas trazendo à tona de forma crítica os diversos sentidos das violências urbanas.

Chacinas, estupros, espancamentos, remoções, transportes lotados, educação e saúde de péssima qualidade, destruição ambiental, são formas de violências sofridas que se manifestam na fala cotidiana dos oprimidos, e que dentro de um processo performático ${ }^{7}$ transformam este campo semântico em arena de negociação, de empoderamento e expressão de uma outra forma de violência, aquela da resistência.

A reapropriação de estéticas da violência e da capacidade destrutiva pelos agentes das performances consiste em uma problematização da passividade que seria a do cidadão comum, colocando em cena outros elementos semânticos que permitem a compreensão das formas de violência para além das figuras do policial, do traficante, ou do assaltante (personagens típicos dessa estética). O mendigo, a travesti, o indígena favelado, a "bicha pobre", ${ }^{8}$ o vândalo ${ }^{9}$ trazem o "quebra-quebra", "o palavrão", o sangue, a sujeira e o lixo como uma proposta estética que subverte as formas de gestão dos corpos e do espaço limpo e sacralizado da higiene social.

A estética segundo Vera Malagutti (2003) é uma via de mão dupla, que pode estar ligada a sujeição, mediadora entre o corpo e a sociedade, mas que também pode ser entendida como um espaço perigoso. Segundo a autora "há alguma coisa no corpo que pode revoltar-se contra o poder que o inscreve” (Malaguti: 2003). As formas de violência traduzidas pelas performances estão relacionadas ao cotidiano urbano e à constante modernização e militarização da cidade.

Este enquadramento sobre a violência, na medida em que enuncia categorias "outras" no campo de negociação, coloca em perspectiva um movimento de circulação de discursos invisibilizados. Conforme Butler:

O que 'escapa ao controle' é precisamente o que escapa ao contexto que enquadra o acontecimento, a imagem, o texto da guerra. Mas se os contextos são enquadrados e se um enquadramento rompe invariavelmente consigo mesmo quando se move através do espaço e do tempo, então o enquadramento em circulação tem de romper com o contexto no qual é formado se quiser chegar a algum lugar. (Butler, 2015: 25)

\footnotetext{
7 A luz de Butler podemos pensar o campo semântico da estética da violência como um espaço de inculcações em que a sedimentação de medos e formação de fantasmagorias estabelecem normas que excluem as violências dissidentes do lugar de reconhecimento ou legitimidade.

8 A expressão "bicha pobre" dá nome a música de Anarkofunk, movimento musical que surge no Rio de Janeiro em 2011, na Ocupação Flor do Asfalto. A música faz menção aos corpos dissidentes e sua forma de vida que se contrapõe ao capitalismo, à heteronormatividade e ao higienismo social. Segue um trecho: "Bicha, preta, pobre, vadia, degenerada, poesia engatilhada e apontada pra tua cara, moro no teu abandono, to comendo do teu lixo, o excesso do espetáculo garante o subsidio, o meu look é de recicle (...)"Ver letra completa: http://www.vagalume.com.br/anarcofunk/ bixa-pobre.html.

9 Vândalo e quebra-quebra, são expressões utilizadas na criminalização do uso da tática Black Bloc nos noticiários da rede Globo. Como forma de subversão os manifestantes tomam o nome para si, utilizando-o em escudos e cartazes. Um dos interlocutores inclusive comenta com orgulho que os vândalos eram os invasores de Roma e uma resistência à opressão do império.
} 
Busco enfim analisar as ações performáticas insurgentes em seu contexto (e neste sentido, contexto é um processo que se atualiza) situacional de possibilidades, como geradoras de conflito, até mesmo enquanto situação ritual, que permite mudanças e reconfigurações dos sujeitos e do próprio ambiente em que atuam.

Os conceitos de agente e agência são acionados na compreensão destas situações de enunciação, de forma a não cristalizar identidades, não se trata de analisar grupos institucionalizados ou organizações políticas convencionais, mas movimentos e estados performáticos alcançados em determinadas situações em que as trajetórias singulares dos agentes se cruzam na construção de agenciamentos coletivos de enunciação heterogêneos.

\section{INSURGÊNCIAS}

A realização dos jogos panamericano no Rio de Janeiro marca o início do processo de mudanças nos espaços na cidade para as instalações de infraestrutura urbana e equipamentos necessários aos jogos. Os movimentos sociais e estudantis começam a organizar-se em formas de assembleias, pensando principalmente a questão da resistência nas ruas as desocupações. A "batalha dos cocos" presente nos discursos dos interlocutores desta pesquisa, ${ }^{10}$ é lembrada como um momento de combate dos estudantes em união com os "camelôs" contra a polícia militar que reprimia uma manifestação contra o aumento das passagens do transporte público.

No início de 2007 mesmo, a tentativa de constituição do MPL. Rapidamente isso se ampliando, com plenárias contra o aumento das passagens. $\mathrm{E}$ todo ano tinha protesto e protestos que chegaram a reunir até 5 mil pessoas na rua, enfrentamento contra o batalhão de choque, dos estudantes mesmo. Jogando coco na cabeça deles. (Estudante e ativista do movimento de ocupações, setembro de 2014)

Nos anos seguintes devido às consequências da revitalização da região portuária outros movimentos começaram a se organizar. As remoções das ocupações Flor do Asfalto, Zumbi dos Palmares e Machado de Assis marcaram um momento de desarticulação, mas também a emergência da performance do Bloco Livre Reciclato.

O Bloco Livre Reciclato surge nesta situação emergencial, uma ação de despejo na região do porto. $\mathrm{Na}$ tentativa de chamar atenção para a violência cometida pelos policiais, os ativistas juntaram mais de 60 latas e, durante horas, tocaram um som sem ritmo nem harmonia. O Bloco Livre Reciclato, além do apoio às ocupações, se formou também em protestos contra o MAR (Museu de Arte Moderna), contra a Copa do Mundo e emerge todos os anos no dia dos mortos (2 de novembro) na Lapa. ${ }^{11}$

O Bloco é uma formação aberta e agrega a todos contemplados pelo ruído das latas e o teor esquizofrênico da performance, por outro lado, provoca outros transeuntes, impede o trânsito dos carros e age contra bares e restaurantes considerados burgueses pelos agentes. Atua também com propaganda distribuindo panfletos que alertam contra o processo de higienização da cida-

10 Os interlocutores que se remetem à "batalha dos cocos" são militantes, estudantes e professores que participaram do protesto que ocorreu em 2007 e que também participaram das manifestações em 2013/2014. Os interlocutores chamam atenção para as semelhanças entre esta situação em 2007 e as manifestações em 2013, no sentido de combatividade à repressão policial e prática de ação direta contra bancos, prédios públicos e multinacionais.

11 Ver: https://www.youtube.com/watch?v=fYnbwtce3nA. 
de e que pedem a organização da população.

As performances do Bloco Livre Reciclato na Lapa e principalmente na Praça da Cruz Vermelha, agregaram outros coletivos e individualidades, formando espaços de livre expressão e contestação política. O Museu de Colagens Urbanas, ${ }^{12}$ o AnarkoFunk e o Coletivo Coiote são coletivos de performances que se agregam ao Bloco Livre Reciclato, mas também atuam separadamente.

O Coletivo Coiote é um grupo nômade de performance que se utiliza da prática escatológica, da modificação corporal e do improviso na construção de um "terrorismo com o cu" ou "pornô-terrorismo". ${ }^{13}$ Protestam contra a heterossexualidade compulsória e contra a violência de gênero, principalmente, voltada para as travestis e pessoas em situação de rua. Ganharam espaço nas mídias (televisão e internet) depois da performance realizada na Marcha das Vadias em junho de 2013, durante a visita do Papa ao Rio de Janeiro. Os agentes do coletivo julgam a performance como necessária ao momento:

A performance que rolou na Marcha das Vadias em 2013, enquanto o Papa Francisco veio ao Brasil, foi uma ação necessária. A Igreja é castradora, colonizadora, assassina. Nos impressionou muito que nada estivesse sendo feito, em termos de ação direta ou algum protesto durante as marchas do JMJ ou a fala do Papa. Enfim decidimos fazer a mulher santificada, a castração dos nossos desejos, a caça às bruxas, o massacre aos povos originários. (Membro do coletivo coiote, abril de 2015).

As manifestações ganham força constituindo-se como atos de solidariedade aos manifestantes reprimidos pela polícia em São Paulo. No Rio de Janeiro encontram suas próprias pautas ligadas aos problemas sociais e urbanos, à luta por moradia, à luta contra a violência policial e à questão do transporte. A tática Black Bloc, já utilizada por militantes anarquistas, ganha popularidade. Alguns militantes contam que a tática chegou a ser ridicularizada em assembleias de organização das manifestações pelo passe-livre, por ser considerada "coisa de europeu" ou fora de contexto. A adesão da população, entretanto surpreendeu até mesmo aqueles que desacreditavam.

A radicalização das ações - muito incentivada pelo Coletivo Coiote em suas performances carregam a estética da máscara negra e canções como "chama a revolta" e "sabote o estado" de Anarkofunk - acontecem no Rio de Janeiro vinculadas a resistência dos atos. A tática Black Bloc é uma performance política que permite tanto a autodefesa quanto a prática da ação direta.

A predação de bancos, monumentos e multinacionais, trabalhada em conjunto com os outros coletivos e agrega ao visual negro a capoeira, o funk e palavras de ordem como "Ih fudeu a favela desceu". Essas performances atualizam as "fantasmagorias urbanas"14 ligadas ao medo da revolta dos escravos no Rio de Janeiro, a tática despontou como um dos principais investimentos coletivos de resistência após os acontecimentos de junho.

12 https://medium.com/@colombinasanglant/museu-de-colagens-urbanas-os-haoukas-da-copa-do-mundo$-64 \mathrm{~b} 45 \mathrm{dbfcf} 2 \mathrm{f}$.

13 Construções imagéticas e performáticas que envolvem o sentido Queer, que escapam a heterossexualidade binária envolvendo a questão do sexo, desejo, corpo como forma de ataque às sexualidades hegemônicas e normativas. 14 Vera Malaguti fala sobre as "fantasmagorias urbanas" no livro "O medo na cidade do Rio de Janeiro". A autora debate sobre a criação do sistema penal brasileiro e sua ligação com o racismo e a busca pelo controle sobre os negros livres que se atualiza no medo urbano da concentração de pobres e das favelas. 
O uso das máscaras e escudos apareceu como técnica de resistência e também como expressão cultural, uma vez que os escudos, bandeiras e as próprias performances como a capoeira e o funk, expressões da cultura popular, trazem mensagens contra a violência policial, lembram os desaparecidos da ditadura, criticam as autoridades governamentais, o racismo e a farsa eleitoral, mostrando também uma multiplicidade ideológica: símbolos de anarquia, comunismo, transfeminismo, antimilitarismo, antifascismo, etc.

A ação direta contra bancos e prédios públicos tornou-se um assunto polêmico e a divisão entre manifestantes pacíficos e "vândalos" foi apenas o início do processo de criminalização das manifestações. É interessante perceber que embora alguns grupos tenham se autodenominado Black Blocs, principalmente nas redes sociais, outros praticantes da tática não tomam a performance enquanto um movimento social, mas como um momento em que se utiliza a tática para permanecer em ato.

Essas performances expressam, de diferentes formas, o empoderamento pela violência, no sentido que desconstroem a passividade de seus corpos e utilizam a prática da ação direta para criação de acontecimentos. Materializam momentos "liminóides" (Turner: 1974) de alteração do espaço, do tempo e do corpo. São eventos potencializados por uma maior reflexividade ou subversão quanto a ordem social. A noção de liminaridade como um momento de suspensão dos valores.

Podem ser entendidas também como ações criativas que partem de situações já conflitivas e tensas e que subvertem a ideia do oprimido como vítima, colocando outros "mundos possíveis” em jogo. Esses agenciamentos produzem afetos que alteram a correlação de forças e ressignificam a percepção sobre tabus relacionados à violência e ao controle sobre os corpos com a possibilidade da transgressão como libertária. Os afetos então circulam pela via do corpo transgressão. As performances produzem efeitos e se expandem no campo imagético, onde o excesso se desdobra. As imagens das performances como uma continuidade deste excesso em duplo sentido, excesso de violência nas imagens e excesso de imagens-violência (Hikiji: 2012).

\section{Método e PerformanCE}

As performances do Bloco Livre Reciclato e Black Blocs permitem a incorporação do público e a implicação do pesquisador. A opção de atuar nas performances inclui o compartilhamento dos riscos que as manifestações implicam, como o conflito com outros manifestantes, a repressão ou mesmo a prisão pela polícia.

Esta forma de "sentir" o campo, se pauta na noção de "Incorporação", de Schechner (2013), pensada como um "ponto de contato", ${ }^{15}$ entre antropologia e performance, no sentido da "experiência como base do conhecimento nativo que é compartilhado por meio da performance" (Schechner, 2013: 27). Schechner pensa a etnografia experimental em contraponto ao cientificismo "objetivo" ocidental que polariza razão e emoção de forma a destituir as impressões

15 Schechner propõe a discussão de três novos pontos de contato entre performance e antropologia: 1. Incorporação; 2. As fontes da cultura humana como performativas; 3. O cérebro como local de performance. Ver: Schechner, 2013. 
causadas pela última de sua cientificidade:

A incorporação, a experiência vivida e a intersubjetividade são fundamentais para abordagens experimentais articuladas na interseção entre performance e etnografia. [...] uma vez que a experiência incorporada escapa ao controle cognitivo e possivelmente o extrapola, expor sua função desestabilizadora no processo de pesquisa pode pôr em período concepções dominantes de conhecimento das quais a legitimidade dos discursos acadêmicos depende de modo crucial. (Schechner, 2013: 29 apud Magnat, 2011: 2013).

A experiência performática permite uma forma distinta de inserção no campo em que o pesquisador é atravessado pelos afetos coletivos enunciados e também tem agência sobre a situação. Recorro também a noção de tempo intersubjetivo de Fabian (2013) em que busco evidenciar a comunicação etnográfica em função da supressão de uma possível negação da coetaneidade ${ }^{16}$ como afirmação da relação de poder do pesquisador sobre os pesquisados através de uma temporalidade hierarquizante.

As performances são analisadas enquanto momentos de transformação dos sujeitos, e também do ambiente e do público afetado por essas ações. Langdon e Pereira (2012) estabelecem a ligação entre rito e performance colocando em perspectiva Van Gennep e Turner (1974). A ruptura com o cotidiano, o afastamento daqueles que se submetem ao rito e, posteriormente, a agregação dos sujeitos com um novo status à sociedade são as três fases que constituem o rito de passagem.

As performances que analiso caracterizam um ritual compartilhado com o público, de forma que a suspensão das normas e valores vigentes não afetam apenas os artistas, mas todos os presentes. Turner (1974) conceitua como situação de "liminaridade"17 este momento de ruptura, que consiste na suspensão dos papeis, na qual as relações estão sujeitas à transformação e ao estabelecimento de uma nova configuração social. Diversamente dos rituais analisados por Turner nas sociedades tradicionais, onde a potencialidade é definida e predomina a coletividade, na contemporaneidade, os rituais tomam formas em que ocorrem em um momento de subversão da ordem sem predeterminação.

\section{Segundo Langdon e Pereira:}

Nos momentos 'liminóides', que não seguem uma periodicidade espacial ou temporal, os eventos são potencializados com maior reflexividade ou subversão quanto a ordem social. Esses momentos encontram-se nas formas através das quais a sociedade pós-industrial se expressa: jogos, festas, brincadeiras, espetáculos, teatro, atos políticos e outros eventos de lazer ou mobilização (Langdon \& Pereira, 2012: 11).

Como um ritual sem direção, mas com intenção, as ações aqui estudadas causam um estado de suspensão em que as reações e as alterações de sentido estão expostas a diferentes devires, o importante é que estas alterações aconteçam.

Para Schechner (2013) existe uma dualidade na ideia de performance, ela pode se constituir enquanto entretenimento (performance-artística), em que as mudanças ocasionadas são momentâneas, ou como ritual, em que as ações potenciais causadoras de mudanças deixam uma marca permanente.

16 Trata- se de uma junção da ideia de contemporaneidade e simultaneidade.

17 Langdon \& Pereira, 2012:11 apud Turner, 1974. 
Os agenciamentos analisados a seguir têm uma relação de atrito com a ideia de performance artística. Podem ser pensados enquanto performance de ação e/ou performance ritual.

\section{O RUÍDO DA REVOLTA}

Podemos analisar as performances do Bloco Livre Reciclato enquanto performances rituais, que se afastam do sentido artístico ligado ao entretenimento, soam mais como uma provocação ao público. O compartilhamento da informação, distribuição de panfletos e a relação de supressão da exterioridade é um convite ao público que se torna agente e tem a possibilidade de "emancipar-se". ${ }^{18}$ Desde 2012 as performances do Reciclato incentivam a organização popular e comunicam informações sobre as injustiças sociais e "violências que atingem os não favorecidos pelo capital". ${ }^{19}$

O Bloco se formou em algumas manifestações um pouco depois de junho, já no período das manifestações pela educação ${ }^{20}$ (setembro-novembro de 2013), compondo com o ruído das latas uma sinfonia do caos junto aos estrondos das bombas e gritos de manifestantes. A construção alegórica desta performance se dá na reciclagem de materiais que produzem ruído encontrados nas ruas. A estética também é produzida com lixo e a maquiagem faz menção à morte. A criação de um espaço caótico, onde cada ator pode expressar-se da maneira que quiser, acaba por trazer à tona o que cada um tem de "doido". Os gritos, o nu, danças frenéticas e o continuo ruído das latas batendo no asfalto perturba os que passam. ${ }^{21}$

Os gritos contra a copa do mundo, pela resistência da Aldeia Maracanã, contra o voto, palavras de ordem das manifestações são enfatizadas no frenesi da festa na Lapa. O indígena que grita contra a copa, a garota nua que se debruça sobre o carro onde o motorista toca a buzina indignado, estudantes e trabalhadores que agarram as latas e se engajam na composição do caos. As pichações nos ônibus parados, um mascarado que sobe no ônibus e pendura em sua fachada uma placa: "Bloco Livre Reciclato, 513 anos de massacres, o dia dos mortos". "A polícia nunca sabe o que fazer" contam alguns agentes que participaram do bloco. Travestis e mendigos se unem ao bloco.

O Bloco Livre Reciclato é uma grande festa em que os mortos voltam para atormentar os cúmplices da violência que se reúnem na Lapa, apáticos aos acontecimentos. O'rourke (2006) recorre a uma 'teoria punkada' proposta por Nyong (2005) para pensar a teoria Queer. Tal esforço epistemológico implica na combinação do "queer" e do "punk" pensando uma referência

18 Me refiro aqui à noção de Espectador Emancipado de Jacques Ranciére (2010). Embora o estudo encontre a noção de subjetivação em Lazzarato (diferente a de Ranciére), a noção de emancipação é utilizada neste momento pensando a ação do Bloco Livre como constituição de um sujeito-morte/vida. "Os vermes não escolhem", a igualdade pode dar-se apenas na morte.

19 Fala de um dos realizadores do Bloco Livre Reciclato.

20 Alguns interlocutores dividem as manifestações de 2013/2014 em períodos onde identifico pelo menos três etapas. A primeira etapa em junho, com a diversidade de manifestantes e reivindicações, caracterizada por multidões heterogêneas; a segunda em que a direita tenta a cooptação das manifestações com a pauta "contra a corrupção" que se dirige ao governo do PT; e a terceira em que as manifestações se esvaziam devido a repressão policial e seguem apenas em algumas cidades. No Rio de Janeiro, especificamente, a luta da educação e a greve geral em outubro de 2013, mantiveram as manifestações e a organização de assembleias com uma constância semanal.

21 Ver: https://www.youtube.com/watch?v=fYnbwtce3nA. 
eternamente anti-identitária. $\mathrm{O}$ autor propõe então uma teoria vadia, um Queer de um mundo sempre por-vir. Podemos pensar o Bloco Livre Reciclato como a proposta deste espaço por-vir, um regime vadiocrático:

O vadio é sempre um marginal, um mau rapaz ou rapariga, um malandro, um punk suburbano que desdenha da lei, razão pela qual o vadio tem de ser policiado, vigiado, sujeito a violência neoliberal. A vadiocracia é um poder da rua, corrupto, um poder ilegal e marginal que reúne num regime vadiocrático, e, portanto, num estado virtual, todos os que representam um princípio de desordem- um princípio, não de caos, mas de desordem estruturada por assim dizer, um princípio de trama e conspiração de afronta ou ofensas à ordem pública (O’Rourke2006: 133 apud Nyong 2005: 66)

Tive a oportunidade de participar algumas vezes do Bloco Livre Reciclato. Em novembro de 2013 na Lapa, já conhecia alguns dos membros que faziam a chamada do bloco. Escutei o ruído de longe e vi que muitas pessoas recortavam os carros na rua Riachuelo batendo latas. Logo um dos participantes me passou uma lata, quase um convite/convocação. O ruído continuo pode soar irritante. A impressão que tive era de que tinha sempre que continuar eu mesma fazendo ruído para que o ruído do bloco não me soasse incomodo. Por fim já não conseguia mais deixar de bater nas latas. Cada qual bate nas latas como quer, as vezes alguns agentes se juntam e tentam algum ritmo mais harmônico que acaba abafado pelas outras latas sem ritmo. Haviam alguns instrumentos, um saxofone e um trompete que rodavam de boca em boca para quem quisesse tocar. $\mathrm{O}$ transito parado e os carros buzinando sem parar, fazendo nova composição com as latas, tornando o ruído cada vez mais alto. As pessoas nos bares tinham reações diversas, algumas sorriam, outras fingiam não ver, outras tampavam os ouvidos. As crianças da rua e as travestis aderiram ao bloco rapidamente, dançando e tocando. O bloco tocou a noite toda, até sobrarem apenas alguns indivíduos já cansados. É interessante notar que nesta época a polícia responsável pelo ordenamento na região (Lapa Presente) ainda não tinha sido implantada. ${ }^{22}$

As outras vezes em que participei acabei com bolhas nas mãos e alguns hematomas por carregar as latas penduradas no corpo. Com as manifestações contra o aumento, o bloco acabava tendo uma duração maior, pois além de acompanhar o ato do início ao fim sempre terminava em festa na Lapa. Com o aumento do policiamento no centro e aproximação do período da Copa em 2014, a realização do Bloco começou a ter que lidar mais seguidamente com a repressão policial. Os interlocutores relatam dois conflitos mais sérios com a polícia, as latas foram confiscadas em uma ocasião e em outra os performers foram detidos e levados à delegacia.

Durante as performances, a reação policial era sempre de irritabilidade, começavam pedindo por favor que parássemos, depois iniciavam provocações verbais. Escutei de policiais coisas como "vocês tocam muito mal", ou "você está suada e fedendo, vai tomar um banho". A reação dos performers em geral era de não responder as provocações. As provocações policiais mostram o quanto o ruído e a sujeira são "violentos" aos olhos, ouvidos e narizes e acaba sendo uma alternativa de violência física sem precisar tocar em quem se combate. Os excessos de ruído, suor e rebeldia demonstram poderes que estão ligados a teoria do dispêndio de modo que o sacrifício do corpo gera mais energia e o ruído se constitui enquanto transbordamento. Quanto mais se toca, mais se quer tocar. A energia do som das latas machucadas reverbera no coletivo todo que assume, então, esse frenesi da música descompassada que se apropria do espaço.

22 Ver: https://www.youtube.com/watch?v=xTu-BS2-Yxs. 


\section{BLACK BLOCS: RESISTÊNCIA E CRIATIVIDADE}

A tática Black Bloc é pensada na pesquisa como performance política. Segundo DepuisDéri (2014) a tática é usada pela primeira vez em 30 de novembro de 1999, na "batalha de Seattle”, em que os manifestantes protestavam diante da reunião da Organização Mundial do Comércio. $\mathrm{O}$ autor afirma que o que caracteriza a tática é a ação direta organizada contra monumentos do Estado e do capital. Apesar dos mitos que colocam "o Black Bloc" enquanto movimento social, o autor afirma, assim como os interlocutores desta pesquisa, que a tática se constitui enquanto acontecimento. A luz de Foucault, penso as resistências como uma operação contra o assujeitamento e estratégias de deslocamento das categorias que emergem no campo. Neste sentido, a categoria Black Bloc deve ser trabalhada mais com relação à suas atualizações performáticas nesta emergência no contexto do Rio de Janeiro e menos com relação as padronizações globais do uso da categoria. Por ser uma categoria que circula no campo de pesquisa se estabelecem diferente noções sobre os Black Blocs veiculadas de diferentes maneiras, pela mídia televisiva, pela mídia ativista ou pelos interlocutores.

Me remeto a tática enquanto performance devido a relação que os agentes encontram com os públicos, com a cidade e com as mídias pela via do corpo. Todos os objetos utilizados na tática adquirem duplo sentido, um de proteção individual e outro de expressão coletiva. A máscara ${ }^{23}$ protege o rosto do gás lacrimogêneo, do spray de pimenta e a identidade individual de cada um, mas também caracteriza o agente como parte desse agenciamento, anunciando sua disponibilidade para resistência e vontade de permanecer em campo. Os escudos têm a mesma utilidade práticas de proteção, mas carregam símbolos e mensagens que transmitem afetos e memórias- em uma das manifestações os escudos carregavam os rostos de desaparecidos da ditadura. As bandeiras utilizadas principalmente como ponto guia quando acontece dispersão e confusão, também levam nomes de organizações populares, regiões da cidade, linhas políticas diferentes, etc. A tática extrapola a questão da resistência e estabelece uma linha de conversação e possibilidade de outros mundos e devires. Em sua emergência no Brasil, penso que ela se forma como um empoderamento popular e de resistência de agentes marginais nos espaços públicos, políticos e centrais da cidade. No caso do Rio de Janeiro, a construção se dá na relação favela/asfalto, inclusive no que tange aos níveis de repressão da polícia. Como afirma uma frase muito veiculada pelos movimentos sociais e pelos interlocutores da pesquisa: "a bala no asfalto é de borracha e na favela é de chumbo".

O corpo combativo aparece com a exigência de um físico forte, ágil e rápido. A construção do corpo na utilização da tática não é feita pela disciplina, as combinações táticas são feitas aos gritos na linha de frente e a comunicação se faz mais importante na formação de um tipo de pedagogia em que se discute temas imediatamente táticos como quando correr e quando resistir, ou, até mesmo, temas mais elaborados como questões de gênero - como se nota no fragmento que segue - além das reiteradas trocas de dicas jurídicas, referentes ao que fazer em caso de captura. Tudo isso entre outros compartilhamentos e rupturas.

A questão da presença das mulheres na linha de frente do Black Bloc, foi uma questão muito forte, que no primeiro momento chegou a ser debatido, não debatido assim, mas sempre tinha alguém que falava: 'não mulher aqui não', e ai de repente todo mundo se colocando: 'como assim mulher aqui não porra?! Claro que pode mulher aqui sim!' E as mulheres tendo um papel primordial nessa luta Black Bloc. (Manifestante e

23 A máscara é um objeto estético polissêmico vinculado à tática Black Bloc mas também à outras formas de resistência. Neste sentido podemos pensar o uso tático empoderador e os muitos atravessamentos simbólicos. 
estudante, novembro de 2014).

Em junho acompanhei duas manifestações que ocorreram na cidade de Pelotas/RS, ${ }^{24}$ o que me permitiu ter uma noção da multiplicidade de reivindicações colocadas pelos manifestantes. Também houve a formação de um Black Bloc, ${ }^{25}$ cujas ações de pichação foram reprimidas por outros manifestantes que reivindicavam um protesto "sem violência". Alguns manifestantes começaram então a exigir que os Black Blocs tirassem as máscaras e mostrassem o rosto, outros apoiaram as ações de pichação e juntaram-se ao bloco. Posteriormente, entrevistando alguns manifestantes no Rio de Janeiro, e que também participaram de manifestações em outras cidades como Salvador e São Paulo, pude compreender que a princípio houve um conflito bastante grande entre aqueles que optavam por protestar utilizando táticas de ação direta e outros que defendiam atos pacíficos e repreendiam ações ilegais. ${ }^{26}$ Porém o conflito constante com a polícia, inclusive em cidades pequenas, mostra indignação com a atitude repressiva da polícia e, ao mesmo tempo, a possibilidade de formas de manifestação mais transgressoras.

No Rio de Janeiro, a revolta foi se potencializando conforme as informações apareciam na internet. A manifestação no Complexo da Maré que terminou em chacina ${ }^{27}$ foi trazida para outras manifestações através de palavras de ordem. O "sumiço" do pedreiro Amarildo ${ }^{28}$ na favela da Rocinha também foi utilizado como forma de ironizar e ridicularizar a posição da polícia constituída por "homens da lei". "Que hipocrisia, essa polícia mata pobre todo dia!", "Não acabou, tem que acabar, eu quero o fim da polícia, militar!", "Cadê o Amarildo?" Não eram solicitações, mas a exigência ou acusação que a população expressava nas ruas.

Cada vez que a manifestação era dispersada com violência, mais pessoas compartilhavam de um momento de opressão, acentuado por toda uma rede de informações construída nos atos. A multidão então começava a relativizar o tabu da violência e um impasse midiático foi travado na busca pela legitimidade da ação "violenta". Segundo Malaguti: "É no campo simbólico e na ação prolongada de inculcação que se desenvolvem relações de concorrência pelo monopólio do exercício legítimo da violência simbólica" (Malaguti, 51: 2003). Neste sentido, a violência temida historicamente no Rio de Janeiro - o medo das favelas e dos pobres - se atualiza na criminalização dos manifestantes, veiculada principalmente pelo meio televisivo. Em contrapartida, outro movimento de legitimação da violência agenciada pelos manifestantes passa a encontrar na internet espaço de expressão.

A tentativa de cooptar os "Black Blocs" para o universo do espetáculo aparecia na televisão como forma de tentar enquadrá-los, "quem são os Black Blocs e o que querem?". As entrevistas produzidas pela Veja e pela Record realizadas com alguns ativistas e páginas no facebook ${ }^{29}$ foram utilizadas para criminalização dos manifestantes processados e classificados como quadrilha armada.

24 As manifestações ocorreram dia 20 e 22 de junho. Ver: https://www.youtube.com/watch?v=sbpT951kjfY. 25 Sobre a tática Black Bloc ver Depuis-Déri: 2014.

26 Esse conflito entre manifestantes pacifistas e "violentos" é trabalhado no documentário "com vandalismo" que acompanha a cotidianidade dos atos no Ceará e a forma como diversos manifestantes foram passando para o lado dos "violentos" ao longo do processo de enfrentamento. Ver: https://www.youtube.com/watch?v=KktR7Xvo09s. 27 Sobre a chacina na Maré ver: http://redesdamare.org.br/wp-content/uploads/2014/06/54-Parasite.pdf 28 Amarildo Souza desapareceu no dia 14 de julho de 2013 após ter sido detido por policiais militares perto de sua casa na favela da Rocinha.

29 Black Bloc Brasil ver: https://www.facebook.com/groups/blackblockbrasil/?fref=ts. 
Pensar os agentes utilizadores da tática Black Bloc enquanto criadores de uma estética da violência e sua ênfase no empoderamento pela combatividade é também a atualização de velhos medos que pairam num certo imaginário que desde os tempos da colônia temem o levante dos escravos e de todos aqueles esmagados pelo sistema penal racista brasileiro. As palavras de ordem subvertem a lógica de que a paz é a ordem, denunciando o momento de guerra, assim como a necessidade da ação direta. $O$ dispêndio aparece novamente com a imanência da destruição criativa, os saques de chocolate nas lojas, o brinde à revolução com bebidas roubadas. A desobediência civil no caso, não opera na lógica da inclusão ou dialogo, mas de um jogo de poder entre os agentes, a cidade e as mídias (TV, Internet).

Num outro registro, é possível também dizer que a tática forma um agenciamento de criação de uma nova subjetividade, que se dá através da dessubjetivação. Segundo Henrique Parra, os Black Blocs que se constituem como grupo político apenas na ação se utilizam de uma "estratégia de dessubjetivação que resiste aos mecanismos de controle, é também uma forma de constituição de atores políticos não-indenitários”. (Parra, 2013: 9)

O figurino funciona como uma forma de proteção contra a repressão e controle policial, mas também como um rechaço as formas de reconhecimento do Estado, além de formar, em meio a massa, a figura da "bandeira negra". Esta tática combativa alastrou a ideia de "ação direta" para a população. Segundo Dupuis-Dèri, no livro Black Blocs (2014):

Os Black Blocs são compostos por agrupamentos pontuais de indivíduos ou grupos de pessoas formados durante uma marcha ou manifestação. A expressão designa uma forma específica de ação coletiva, uma tática que consiste em formar um bloco em movimento no qual as pessoas preservam seu anonimato, graças, em parte, às máscaras e roupas pretas. (Depuis-Déri, 2014: 10).

Se a negociação com o Estado se dá por meio da afirmação identitária e a luta da inclusão social pelas bandeiras coloridas, o Black Bloc nega qualquer tipo de identidade, ainda que temporária, e afirma na destruição seu transbordamento corporal, desterritorializando espaços e dando novos sentidos à cidade.

Corpos disciplinados por toda a vida que, naquele momento, se desconstruíam transformados em hordas mascaradas que afrontavam contra símbolos do capital e do estado, rompendo bancos, incendiando monumentos, enfrentando a repressão policial. Neste sentido, corpos que constituem uma dupla resistência, enfrentando os dispositivos de controle e também rompendo as amarras de seus corpos disciplinados. Constituição de um novo sujeito desterritorializador de seu próprio corpo. Podemos pensar também o Black Bloc como constituição de uma "Zona Autônoma Temporária” (Hakin Bey: 2004), ${ }^{30}$ um levante em que as leis, hierarquias e a própria moral são destituídas de seu poder consagrador para dar espaço à criatividade e à subversão.

As máscaras ganham diversidade, caveiras, o vilão Jason ou $\mathrm{V}$ de vingança também utilizado pelo movimento de hackers Anonimous, aparecem como alternativa ao capuz negro. A utilidade não é só a proteção da identidade individual, mas também o posicionamento do lado dos "vilões" que aterrorizam a sociedade. O "A" de anarquia ao lado da foice e martelo comunista, o A.C.A.B. (All Cops Are Bastards) e outras frases demonstram a popularização de valores libertários que se misturam.

30 Segundo o autor, TAZ é um conceito autoexplicativo pela ação e não pode ser definido. É vinculado a ideia de "levante" e "festivais". 
Há uma troca de afetos que faz parte desse momento de corpo coletivo, na qual o empoderamento sobrepõe a impotência frente ao "inimigo", no caso a repressão policial, uma mistura de medo e euforia que propicia a agilidade e o instinto de sobrevivência, o ataque e destruição em todos os momentos possíveis. O forte cheiro do gás lacrimogêneo e o perigo eminente tornam o medo constante, porém a euforia e a alegria também compõem as sensações na formação Black Bloc. É necessário correr o máximo que puder estar atento as bombas, aos policiais, cuidar daqueles atingidos pelo gás, cuidar-se com as pedras e garrafas que voam sobre nossas cabeças em direção às vitrines, carros e bancos, e evitar, através de todos os meios necessários, ser capturado. A captura é o processo de interdito que barra o indivíduo e o tira do corpo da revolta, o identifica, cataloga, reprime e encarcera.

A primeira manifestação em que pude agir junto aos que se utilizavam da tática foi em outubro, quando já havia um certo esvaziamento em termos de quantidade de pessoas, mas a politização e a centralidade na pauta da educação davam um caráter qualitativo de força e apoio mútuo entre os manifestantes.

A manifestação foi chamada pela Frente Independente Popular em apoio a greve dos professores. Cheguei por volta das $19 \mathrm{~h}$ na Cinelândia, acompanhada de uma manifestante. Era a segunda vez que vinha ao Rio de Janeiro, cidade nova, campo de pesquisa novo. Estranhamento, medo. Chegamos ao centro e já me impressionei com a quantidade de viaturas e policiais na rua. Horário de pico, centro, espaço caótico, fluxo intenso de pessoas indo para suas casas. Chegamos à Cinelândia, uma quadra antes eu já podia ouvir a voz de uma mulher no megafone. Nos aproximamos e entramos na multidão. Várias bandeiras, não consegui identificar nenhuma, todas siglas desconhecidas, algumas negras. Em cima do caminhão um homem agora discursa sobre a greve, expõe as reivindicações, critica o governo e o próprio sindicato que havia boicotado os grevistas. Pede por revolução. Uma professora sobe e exprime apoio aos Black Blocs: "O Black Bloc é meu aluno, mexeu com ele mexeu comigo!".

Neste momento sou apresentada a alguns indivíduos mascarados ao meu redor. A manifestante diz: é para não ser confundida com P2 $2^{31}$. Ela coloca a camisa na cabeça e faz uma touca ninja, todos ao meu redor começam a mascarar-se, faço o mesmo. Faz calor, o suor escorre na testa e molha a camisa, é difícil respirar, a touca tapa os ouvidos e o nariz. Somente posso enxergar as costas da pessoa a minha frente. Mesmo com os sentidos debilitados sinto mais segurança junto aos outros. Olho para cima, uma professora no caminhão de som grita "O Black Bloc é meu amigo", a horda responde com um som visceral, um grunhido: UH UH UH UH UH! Não sei ao certo porque fazem isso, mas todos fazem. Alguém grita: "Deixa passar a revolta popular" e então sinto a multidão se mexer. De dentro da massa não dava para saber em quantos estávamos, mas não eram poucos. Somente vai em direção à rua o Black Bloc, deixando os outros manifestantes e o caminhão de som para traz. Senti que foram como cinco minutos eufóricos de canto. Bandeiras negras tremulavam e a postura dos que estavam ao meu redor era inclinada para frente, alguns com braço esquerdo erguido e punho cerrado. De repente, alguém grita: P2, pega o P2. Uma bomba explode e a massa se espalha para todos os lados. No espaço que ficou na rua antes preenchido pela massa pelo menos cinco policiais seguram um corpo no chão. Eles tiram a máscara da ativista capturada. Mais bombas, por algum momento só sinto medo, meus olhos enchem de lágrimas e meu estomago revira, é o gás lacrimogêneo. Todos correm em todas as direções em que o gás ou a polícia ainda não tomaram conta.

31 Policial infiltrado. 
Eu também corro e me surpreendo com os que correm ao meu lado, alguns corpos animados, leves, rápidos, eles gritam UH UH UH UH UH. Pedras voam sobre a polícia, corremos em direção aos becos que levam à Lapa. As ruas estreitas já estão repletas de pequenos Black Blocs que constroem barricadas com lixo, latas e fogo. Reparo que são corpos pequenos, tenho certeza que alguns são crianças. Olho para traz, uma fileira de homens, coletes, capacetes, cassetetes que produzem um estrondo apavorante quando ressoa no escudo. Eles se aproximam aos poucos, com seus passos marcados em marcha. De repente um grupo aparece em outra esquina, uma bandeira negra, reagrupamento de vultos. $\mathrm{O}$ confronto dura horas, bombas vindas de todos os lados impedem a visão e tornam o ar irrespirável. Mas os manifestantes parecem incansáveis, mantendo sua postura combativa até algumas horas mais tarde em que o movimento vai se esvaziando. Os manifestantes aos poucos desaparecem, voltam ao seu estado civil e às suas casas. Com exceção dos que foram detidos e levados para depoimento e identificação.

Este cenário de forte repressão policial, de negociação das opiniões veiculadas pelas mídias e de conflitos sobre as formas de negociação com as instâncias do Estado - ataque e enfrentamento à polícia e formas de expressão diversas nas manifestações - exige uma problematização das relações de poder. Não se trata de uma divisão clara entre o Estado e a população. Os conflitos internos são muitos e a heterogeneidade da multidão acentua relações de classe, gênero, raça, entre outras questões tratadas nas assembleias e colocadas pelos movimentos sociais. O exercício do poder se acentua nos discursos partidários na tentativa de liderança das manifestações, na tentativa de exclusão das mulheres da frente de luta por ativistas homens, ou nos conflitos entre pacifistas e Black Blocs. As manifestações constituem um campo vasto em que o poder é exercido de diferentes maneiras e estas negociações se estendem para o campo midiático. As performances são o meio de empoderamento daqueles que não ocupam posições de "excelência" do exercício de poder, e criticam as posições de privilégio, construindo um espaço de desestruturação das relações de poder. ${ }^{32}$

\section{COIOTE: PERFORMANCE DE VIDA E MORTE}

O Coletivo Coiote, ${ }^{33}$ cujas performances abrangem temas como violência de gênero e colonização do corpo expressos de forma a provocar diversos devires quando levadas para as manifestações, teve seu público ampliado pela forte repercussão midiática.

O Coletivo Coiote também pode ser pensado enquanto performance ritual, pensando a relação que os performers estabelecem com seu próprio corpo. No público as mudanças podem ser passageiras, porém a reverberação polêmica das performances e o teor provocador mantém os afetos por mais tempo em cenário. Os agentes não se identificam enquanto artistas e entendem suas performances enquanto ação direta e possibilidade de desconstrução e descolonização de seus corpos. As performances do coiote também podem ser entendidas como performances que carregam fragmentos das contraculturas Queer e punk.

32 Ver: https://www.youtube.com/watch?v=h0wAA4fXTsI.

33 Ver: https://www.youtube.com/watch?v=o87c9YINwZo. 
Michael O'rourke realiza uma reflexão sobre a teoria Queer a partir dos conceitos de "auto-imunidade" ${ }^{44} \mathrm{e}$ "democracia-por-vir, como proposta de um queer vadio, aberto, continuo. Se o gênero se constitui, para Butler, como uma sedimentação de performatividades que gerem a norma e uma norma que exclui e gera dissidências e sujeitos abjetos, a auto-imunidade pode ser pensada como um movimento de construção de uma monstruosidade que não deixa a norma se sedimentar.

As performances realizadas pelo coletivo coiote lançam mão o tempo todo de estratégias auto-imunizadoras quando expõem seus corpos violentados. Porém ao expor essa vulnerabilidade, não o fazem buscando comoção do Estado ou de uma "opinião pública" genérica, mas no intuito de catalisar uma revolta. As performances estão voltadas aos marginalizados extreme, aos vulneráveis e precarizados como abertura para uma aliança coletiva.

A sua estética vincula artefatos da religião afro, modificações corporais, como costura da boca e das genitais, o uso do nu e da máscara negra e a musicalidade do "AnarkoFunk". O nu tem uma relação muito forte com as extensões do corpo ao espaço. Para Bataille, o nu é o que substitui o isolamento do ser pela continuidade, pois a "nudez se opõe ao estado fechado, isto é, ao estado de existência descontinua” (Bataille, 1987: 17). A continuidade é representada pelos performers nas apresentações de orgias públicas onde o sexo ao vivo e na rua é mostrado de forma distinta do convencional. Suas extensões são objetos atípicos, como as cruzes ou nabos introduzidos nos anus e vaginas dos agentes. O sexo homossexual e os sadismos e masoquismos - fezes e urina passados nos corpos - performa a escatologia constitutiva do coletivo. A escatologia pode ser entendida como parte do excesso em que o corpo explode liberando fluídos que ultrapassam a barreira dos outros corpos presentes. $\mathrm{O}$ cheiro produz a energia do nojo e outra escatologia: o vomito. Não foram poucas as pessoas do público que vi taparem a boca e se retirarem contendo o vomito.

O Coletivo Coiote sofre hoje perseguição política no processo de criminalização de duas performances ${ }^{35}$ : uma, em junho de 2013, na Marcha das Vadias, em que os atores quebraram imagens de santo e enfiaram cruzes nos anus, enquanto cantavam "Chama a Revolta", som de AnarkoFunk; a outra performance, em junho de 2014, em uma festa na Universidade Fluminense (UFF), em Rio das Ostras, em que o coletivo montou um cenário com velas, um crânio humano e outros objetos. Na ação uma das performers deita e introduz uma bandeira do Brasil na vagina que é costurada em seguida. A performance foi categorizada na mídia como "ritual satânico" e o processo recaiu sobre o professor responsável pelo evento, que se manifestou a partir de uma nota esclarecedora, sobre a performance. ${ }^{36}$

\footnotetext{
34Auto-imunidade é para Derridá o movimento de combate das próprias forças de resistência, proporcionando uma abertura radical ao outro. O contraste aqui é entre uma imunização absoluta, onde o organismo repele toda diferença enquanto corpo estranho e a auto-imunização onde o corpo minando as próprias formas de resistencia é capaz de criar uma abertura, uma espécie de hospitalidade incondicional, ao absolutamente outro.

35 As performances tiveram muita repercussão midiática, tanto jornalística como posicionamentos em blogs e sites. Alguns links que discutem os acontecimentos: http://www.revistaforum.com.br/blog/2014/06/performance-feminista-e-interpretada-como-ritual-satanico/ ; http://oglobo.globo.com/sociedade/educacao/festa-satanica-da-uff-tera-ato-de-apoio-12687369; http://zh.clicrbs.com.br/rs/noticias/proa/noticia/2014/06/chocar-e-a-palavra-de-ordem-no-feminismo-contemporaneo-4531765.html

$36 \mathrm{http} / /$ g1.globo.com/rj/regiao-dos-lagos/noticia/2014/06/professor-da-uff-declara-apoio-total-aos-organizadores-de-festa-polemica.html. Ver também: https://www.youtube.com/watch?v=bq1WyPriFZQ\&oref=https\%3A\%2F\%2Fwww.youtube.com\%2Fwatch\%3Fv\%3Dbq1WyPriFZQ\&has_verified=1
} 
Nomadismo que não se dá pela desertificação, mas desterritorialização em excesso. As performances do Coletivo Coiote atuam de forma a sujar o ambiente, espalham lixo, as vezes arremessando contra o público que os assiste, defecam no piso e muitas vezes utilizam as fezes para atacar restaurantes finos e bares chiques. A questão do excesso e da explosão aparece nas falas das performers que se pensam enquanto "korpos-bomba", no sentido de que elas mesmas se pensam enquanto monstras, recorrem as categorias marginalizadas como forma de empoderamento em movimento coletivo:

\begin{abstract}
Nos rebelamos contra opressões vindas do colonialismo e capitalismo, somos aliadas aos oprimidxs de gênero, pessoas não aceitas socialmente, radicalizadas, marginalidades extremas, corpos periféricos não generalizados, corpos sujos e demonizados pelas instituições castradoras. Pensando em guerra de classes, descolonização, morte ao patriarcado e esclarecimentos sobre os privilégios que oprimem a marginalidade a qual somos impostas, como a horizontalização pode ser uma cilada, etc. Queremos a quebra total, colamos com a galera da rua, pensamos em fortalecimentos afetivos dentro da margem, somos todas korpos-bomba!
\end{abstract}

\title{
Conclusão
}

O que torna comum estas três formas de insurgência, é a maneira como constroem um ambiente propício para sua atuação e a ação direta pela via da estética da violência. A transformação do corpo se constitui na identificação das técnicas disciplinares e as manifestações comportamentais, produzindo uma desconstrução através da performance. $\mathrm{O}$ agente em questão percebe a recusa do reconhecimento de seu status como sujeito e se recusa ao mesmo tempo a reproduzir as normas que o assujeitariam. Antes, transforma o corpo em uma expressão libertária dos sentidos contra a normatividade. As performances criam um campo dramático que estabelece a violência causada na destruição de um banco ou na costura da própria boca, como acionadoras da violência comum, aquela ocasionada pela desigualdade social e pelo silenciamento.

A atualização estética da violência traz na noção de dispêndio uma nova gestão do corpo, aquele que enfrenta a violência enquanto agente e não mais como vítima. Só podemos destruir aquilo que é nosso, destruir é uma forma de consumo, o autoflagelo é a expressão não falada de "Este corpo é meu". O empoderamento se dá em uma relação agonística de destruição e autodescolonização, enfatizando a caracterização estética da esquizofrenia, da sujeira, da homossexualidade como existências potenciais, afirmadoras de sentido e que denunciam a passividade enquanto cúmplice da violência higienista.

O corpo transgressão, na tradução do campo semântico da estética da violência, tende a chocar e conflitar com o público, mas é também criador de um estranhamento. O choque, seguido de estranhamento e depois o esforço do entendimento de um sentido tão dilacerador que atravessa o sujeito, é um exercício antropológico que as performances colocam na rua como um espaço político de compartilhamento da revolta. Neste sentido volto a afirmar o caráter intersubjetivo desta pesquisa:

Se a coetaneidade, o compartilhamento de um tempo presente, é uma condição da comunicação e o conhecimento antropológico tem suas origens na etnografia que é claramente um tipo de comunicação, então o antropólogo qua etnólogo não está livre para 'conceder' ou 'negar' a coetaneidade a seus interlocutores. Ou ele se submete à condição da coetaneidade e produz conhecimento etnográfico ou se ilude na distância temporal e não alcança o objeto de sua busca (Fabian, 2013:67). 


\section{REFERÊNCIAS BIBLIOGRÁFICAS}

Artaud, Antonin. 2006. O teatro e seu duplo. São Paulo: Martins Fontes.

Bataille, Georges. 1975. A Parte Maldita. Rio de Janeiro: Imago editora ltda. 1987. O erotismo. Porto Alegre: L\&PM.

Butler, Judith. 2015. Quadros de Guerra: Quando a vida é passível de luto? Rio de Janeiro: Civilização Brasileira.

2009. "Actos performativos y constituición del género: un ensayo sobre fenomenología y teroria feminista”. Pp.321-336. in Revista de Antropologia Iberoamericana 4(3). (http:// pt.scribd.com/doc/137843298/Judith-Butler-Performatividad-Precariedad-y-PoliticasSexuales).

Deleuze, Giles. 1995. "Post-escriptum sobre las sociedades de control”. Conversasiones. Pp.219226. Edición electrónica de (www.philosophia.cl) / Escuela de Filosofía Universidad ARCIS.

Díaz, Elvira Burgos. 2013. "Desconstrução e subversão: Judith Butler.” Pp. 441-464 in Sapere Aude 4 (7).

Dupuis-Déri, Francis. 2014. Black Blocs. São Paulo: Veneta.

Fabian, Johannes. 2013. O tempo e o Outro: Como a antropologia estabelece o seu objeto. Rio de Janeiro: Editora Vozes.

Foucault, Michel. 1988. História da sexualidade 1: A vontade de saber. Rio de Janeiro, Edições Graal.

Hakim Bey. 2004. TAZ: Zona Autonôma Temporária. São Paulo: Conrad Editora do Brasil.

Hikiji, Rose Satiko Gitirana. 2012. Imagem-Violência: etnografia de um cinema provocador. São Paulo: Terceiro Nome.

Langdon, Esther Jean; Pereira, Èverton Luís (org.). 2012. Introdução: do ritual à performance. Rituais e Performances: iniciações em pesquisa de campo. Florianópolis: UFSC/ Departamento de Antropologia.

Lazzarato, Maurizio. 2006. Por una politica menor. Acontecimiento y política em las sociedades de control. Madrid: Traficantes de sueños.

Lefevbre, Henri. 1986 La production de l'espace. París: Anthropos.

Malaguti, Vera. 2003. O medo na cidade do Rio de Janeiro: dois tempos de uma bistória. Rio de Janeiro: Revan.

O’Rourke, Michael. 2006. "O que há de queer na teoria queer por-vir?” Pp.127-140 in Revista Critica de Ciências Sociais [online] 76. (http://rccs.revues.org/870)

Ranciére, Jacques. 2010. El espectador emancipado. Buenos Aires: Manantial.

Schechner, Richard. 2013. "Pontos de Contato Revisitados" Pp. 23-66. Revista de Antropologia 56(2), São Paulo.

. 2000. Performance, teoria e práticas intelectuales. Buenos Aires: Libros de Rojas.

Turner, Victor. 1974. O Processo Ritual Estrutura e Anti Estrutura. São Paulo: Vozes.

\section{BOdY TRANSGRESSION: VIOLENCE TRANSLATED INTO PERFORMANCES OF "BLACK Blocs", "Coletivo Coiote" and "Bloco Livre Reciclato"}

This article, situated in the areas of visual anthropology and performance studies, analyzes the idea of "Body Transgression" which seeks to constitute an insurgent, rebellious and not submissive body. The Brazilian insurgent movements "Bloco Livre Reciclato", "Coletivo Coiote" and "Black Blocs" are 
discussed as a political economy of the body, focused on the transformation of bodily management. This notion carries the idea of deconstruction of the docile body, as formulated by Foucault. The setting of those manifestations are the streets of Rio de Janeiro. The analysis is based on the semantic field of aesthetics of violence and the insurgent movements are studied in relation to the image-violence of their performances.

Keywords: insurgency, transgression body, crowd, image-violence, nomadism

Recebido em: 2015-01-31

Aceitado em: 2015-10-13 